\title{
Visual Impairment and Functional Classification in Children with Cerebral Palsy
}
M. Rauchenzauner ${ }^{1,2, *}$
K. Schiller ${ }^{1, *}$
M. Honold ${ }^{2}$
I. Baldissera ${ }^{3}$
R. Biedermann ${ }^{4}$
B. Tschiderer ${ }^{3}$
U. Albrecht ${ }^{2}$
C. Arnold ${ }^{2}$
K. Rostasy ${ }^{5}$

${ }^{1}$ Department of Pediatrics and Neonatology, Kliniken OstallgäuKaufbeuren, Kaufbeuren, Germany

2 Division of Pediatric Neurology, Department of Pediatrics, Medical University of Innsbruck, Innsbruck, Austria

${ }^{3}$ Department of Ophthalmology and Optometry, Medical University of Innsbruck, Innsbruck, Austria

${ }^{4}$ Department of Orthopedics, Medical University of Innsbruck,

Innsbruck, Austria

${ }^{5}$ Department of Pediatric Neurology, Children's Hospital Datteln, Witten/Herdecke University, Datteln, Germany

Neuropediatrics 2021;52:383-389.

\begin{abstract}
Address for correspondence Rauchenzauner Markus, MD, PhD, Department of Pediatrics and Neonatology, Kliniken OstallgäuKaufbeuren, Dr.-Gutermannstr. 2, 87600 Kaufbeuren, Germany (e-mail: markus.rauchenzauner@kliniken-oal-kf.de).
\end{abstract}

Abstract

Keywords
- cerebral palsy
- visual impairment
- functional
classification
- GMFCS
- BFMF

Background Cerebral palsy (CP) is the most common motor impairment in childhood and often accompanied by a broad spectrum of comorbidities. Data are sparse concerning visual impairment ( $\mathrm{VI})$ and functional classification among CP children. Objective The objective of this study was to analyze the prevalence of $\mathrm{VI}$ among children with $\mathrm{CP}$ and to investigate a possible association between VI and Gross Motor Function Classification System (GMFCS) and the Bimanual Fine Motor Function (BFMF). Methods In this hospital-based study, records of 200 children with CP aged 2 to 17 years were reviewed.

Results Overall, VI was found in $59.5 \%$ of children with CP. Prevalence of VI was higher when compared with non-CP children. A correlation between GMFCS as well as BFMF and severity of $\mathrm{VI}$ was found. Children with severe CP were at greater risk for severe $\mathrm{VI}$, especially cerebral VI compared with children with mild CP.

Conclusion $\mathrm{VI}$ is a significant problem in children with $\mathrm{CP}$ and is correlated with motor function. Children with CP should undergo detailed ophthalmologic and orthoptic assessment to enable early intervention.

\section{Introduction}

Cerebral palsy (CP) is a nonprogressive but permanent motor impairment beginning in the early childhood often accompanied by a variety of comorbidities such as epilepsy, mental retardation, and orthopaedic problems. ${ }^{1-3}$ During the last decade, major efforts have been undertaken to improve the standard of care.

These authors contributed equally to this article.
Besides the motor disorder, developmental and performance challenges in children with $\mathrm{CP}$ are also influenced by disturbances of vision as already described in the early 1980 s. $^{4}$ Studies point toward a variable incidence of ocular abnormalities such as refractive errors, nystagmus, strabismus, amblyopia, and cerebral visual impairment (CVI). ${ }^{4-6}$ The majority of children with $\mathrm{CP}$ had refractive errors and strabismus or even severe visual loss. ${ }^{5,7}$ In a systematic review about co-occurring impairments, 1 in 10 children with $\mathrm{CP}$ was blind. $^{8}$ Additionally, visual-perceptual

(c) 2021. Thieme. All rights reserved. Georg Thieme Verlag KG, Rüdigerstraße 14, 70469 Stuttgart, Germany
DOI https://doi.org/ 10.1055/s-0040-1722679. ISSN $0174-304 X$. 
impairment was evident in 40 to $50 \%$ of children with $\mathrm{CP}^{9}$ and was also linked to reduced quality of life. ${ }^{10}$ Children with CP showed also a high incidence of visual field defects (11\%). ${ }^{4}$ $\mathrm{CVI}$ was also frequently found children with $\mathrm{CP}$ ranging from 50 to $70 \%$ incidence. $^{11}$

Data concerning frequency and especially subtype of visual impairment (VI) on the basis of a specific pediatric ophthalmology examination among $\mathrm{CP}$ children are sparse. Comparing different subtypes of $\mathrm{CP}$, children with tetraplegia, diplegia, and hemiplegia showed different neuro-ophthalmological profiles calling for a distinct assessment of VI in children with $\mathrm{CP} .{ }^{12}$ In children with tetraplegic $\mathrm{CP}$, the most severe VI was found characterized by highly reduced visual acuity, oculomotor abilities, and abnormal eye movements. $^{12}$

Two of the most important scales to measure functioning of children with CP objectively are the Gross Motor Function Classification System (GMFCS) and the Bimanual Fine Motor Function (BFMF). ${ }^{11}$ Each system has five levels representing differences in function that are meaningful in daily life. GMFCS and BFMF scores correlate with each other. ${ }^{13}$ It raises the question whether VI could also be associated with functional classification in children with $\mathrm{CP}$ which would be of practical clinical importance.

The aim of the study was to determine the prevalence of VI among children with $\mathrm{CP}$ and a potential association of type and severity of VI with $\mathrm{CP}$ subtype and the functional classification according to GMFCS and BFMF.

\section{Methods}

All patients included in this study had been examined and treated at the Department of Pediatrics, Medical University Innsbruck, Austria. Diagnosis of $\mathrm{CP}$ was made using the definition criteria of Surveillance of Cerebral Palsy in Europe (SCPE). ${ }^{14}$

Before being registered to the $\mathrm{CP}$ database of Tyrol, informed consent was obtained from patients and/or their parents in accordance with the Declaration of Helsinki. The $\mathrm{CP}$ register of Tyrol and this study was approved by the local ethics committee.

\section{Register}

In this retrospective population-based study, 200 children with CP were registered in the CP register, Tyrol, Austria $(n=200) .{ }^{15}$ The children had to be born in Tyrol, Austria or living there for at least 2 years to be eligible. One hundred twenty-nine children had a detailed ophthalmological examination at the Department of Ophthalmology in Innsbruck, and 71 children have been examined elsewhere.

\section{Neurologic Examination and Classification}

Subtypes of CP were defined as bilateral spastic (BS), unilateral spastic (US), dystonic, choreoathetotic, and ataxic CPs. ${ }^{14}$ To further classify at a functional level, two standardized functional grading systems, the GMFCS ${ }^{16}$ and the BFMF, ${ }^{17}$ were applied.
The GMFCS classifies as follows: level I: walks without limitations; level II: walks with limitations; level III: walks using a hand-held mobility device (canes, crutches, walkers); level IV: self-mobility with limitations, may use powered mobility; and level V: transported in a manual wheelchair. ${ }^{16}$ Analogous to the GMFCS, the BFMF scale has been developed for functional grading of the upper limbs. ${ }^{17}$ Levels I and II were combined in the analysis as milder and levels III to $\mathrm{V}$ as severe GMFCS and BFMF.

\section{Ophthalmologic Examination and Classification}

Ophthalmologic and orthoptic assessment were performed at the Department of Ophthalmology, Medical University Innsbruck, Austria. Data on VI were collected by reviewing all medical records available at the Department of Ophthalmology of the 200 children with CP involved in the study. Thereof, 129 (64.5\%) cases with detailed ophthalmological findings of the Department of Ophthalmology, Medical University Innsbruck were eligible. Seventy-one children have been examined elsewhere.

Vision in children with CP (according to SCPE) was classified as (1) no VI, (2) mild-moderate VI, or (3) severe VI. ${ }^{11}$ Severe VI was defined as visual acuity loss of $>6 / 60$ (Snellen) or $<0.1$ (decimal) in both eyes, for example, blind or no useful vision (after correction on the better eye) or if diagnosis of severe CVI was made.

Visual acuity (best corrected) was measured (age appropriate) by using optotype testing on a Snellen's chart (numbers, letters, Landolt rings, or LEA symbols for children) or alternatively by using visual evoked potentials or the method of "preferential looking." Visual acuity was classified as (1) $>0.8$; (2) 0.7 to 0.4 ; (3) 0.3 to 0.1 , and (4)<0.1.

Refractive errors, such as myopia $(<-1.5 \mathrm{D} ;-1.6 \mathrm{D}$ and $-4 \mathrm{D} ;>-4 \mathrm{D})$, hyperopia $(<+1.5 \mathrm{D} ;+1.6 \mathrm{D}$ and $+4 \mathrm{D} ;>+4 \mathrm{D})$, astigmatism (yes/no), and anisometropia ( $>1.5 \mathrm{D}$ between the spherical equivalent of the right and left eyes), were measured with cycloplegic retinoscopy. Astigmatism was diagnosed by using a keratoscope, an ophthalmometer, or computed corneal topography.

Strabismus (esotropia or exotropia) was diagnosed by using the cover test, Brückner's and/or Hirschberg's test.

CVI is defined as all visual dysfunctions caused by damage to, or malfunctioning of, the retrochiasmatic visual pathways in the absence of damage to the anterior visual pathways or any major ocular disease. ${ }^{18-20}$ The term covers most of the diverse and complex impairments that might occur in children with $\mathrm{CP}$, such as decreased visual acuity and contrast vision, visual field defects, disorders of color and stereoscopic vision, reduced accommodation, unstable fixation, dysmetric and imprecise saccadic eye movements, decreased perception of depth and pursuit movements, and a limited ability to recognize objects and faces. ${ }^{18}$

Optic atrophy (fundoscopy shows pale optic disc) describes various forms of optic nerve's axon degeneration potentially resulting in vision loss or visual field defects.

Retinopathy of prematurity (ROP) is a proliferative disease of the retina, diagnosed by ophthalmoscopy and categorized into stages I to $\mathrm{V}$ disease. 
Table 1 Visual impairment and ocular abnormalities related to CP subtype

\begin{tabular}{|c|c|c|c|c|c|c|c|}
\hline & Mild VI & Severe VI & Strabismus & $\begin{array}{l}\text { Retinopathy of } \\
\text { prematurity }\end{array}$ & $\begin{array}{l}\text { Cerebral visual } \\
\text { impairment }\end{array}$ & $\begin{array}{l}\text { Atrophy/ } \\
\text { hypoplasia } \\
\text { of the optic } \\
\text { nerve }\end{array}$ & Nystagmus \\
\hline N & 87 & 32 & 69 & 17 & 16 & 15 & 13 \\
\hline BS-CP & 42 & 26 & 45 & 12 & 14 & 12 & 10 \\
\hline US-CP & 30 & 4 & 17 & 2 & 1 & 3 & 2 \\
\hline Choreoathetotic CP & 8 & 1 & 3 & 3 & 0 & 0 & 0 \\
\hline Dystonic CP & 5 & 1 & 4 & 0 & 1 & 0 & 0 \\
\hline Ataxic CP & 2 & 0 & 0 & 0 & 0 & 0 & 1 \\
\hline
\end{tabular}

Abbreviations: BS, bilateral spastic; CP, cerebral palsy; VI, visual impairment; US, unilateral spastic.

\section{Statistics}

Data are presented as absolute numbers and percentage in parenthesis when appropriate. Normal distribution of the data was assessed using the Kolmogorov-Smirnov's test.

Contingency tables and Pearson's chi-squared test were applied. Pearson's correlation coefficient was used to determine statistical significance and correlation for categorical variables.

All analyses were performed two tailed with $p$-values $\leq 0.05$ indicating statistical significance. Statistical analyses were performed using the Statistical Package for Social Sciences for Windows (SPSS Inc., version 26.0, Chicago, Illinois, United States).

\section{Results}

\section{Patients}

Overall, $200 \mathrm{CP}$ children $(f=90[45 \%])$ aged 2 to 17 years (mean $=11.1 \pm 4.2$ years) were included in the study. There- of, 100 (50\%) children were diagnosed with BS-CP and 74 (37\%) had US-CP. Twenty-two (11\%) children were identified with dyskinetic CP of whom 13 (6.5\%) had a choreoathetotic CP and 9 (4.5\%) a dystonic CP. Four (2\%) children were diagnosed with ataxic $\mathrm{CP}$.

Of all children with CP, 120 (60\%) patients were classified as GMFCS levels I and II, 73 (36.5\%) levels III to V and 7 patients were unknown concerning GFMCS. One hundred twenty-seven (63.5\%) children had BFMF levels I and II, 62 (31\%) had levels III to V, and 11 children were unknown concerning BFMF.

\section{Visual Impairment and Ocular Abnormalities}

Of all children with CP reviewed ( $n=200)$, VI was diagnosed in 119 (59.5\%) patients. Eighty-seven (43.5\%) had a mildmoderate VI, and 32 (16\%) showed severe VI. Frequencies of ocular abnormalities related to CP subtype are presented in -Table 1. Overall, most common were strabismus in 69 (34.5\%) and refractive errors in 63 (31.5\%) children (-Fig. 1).

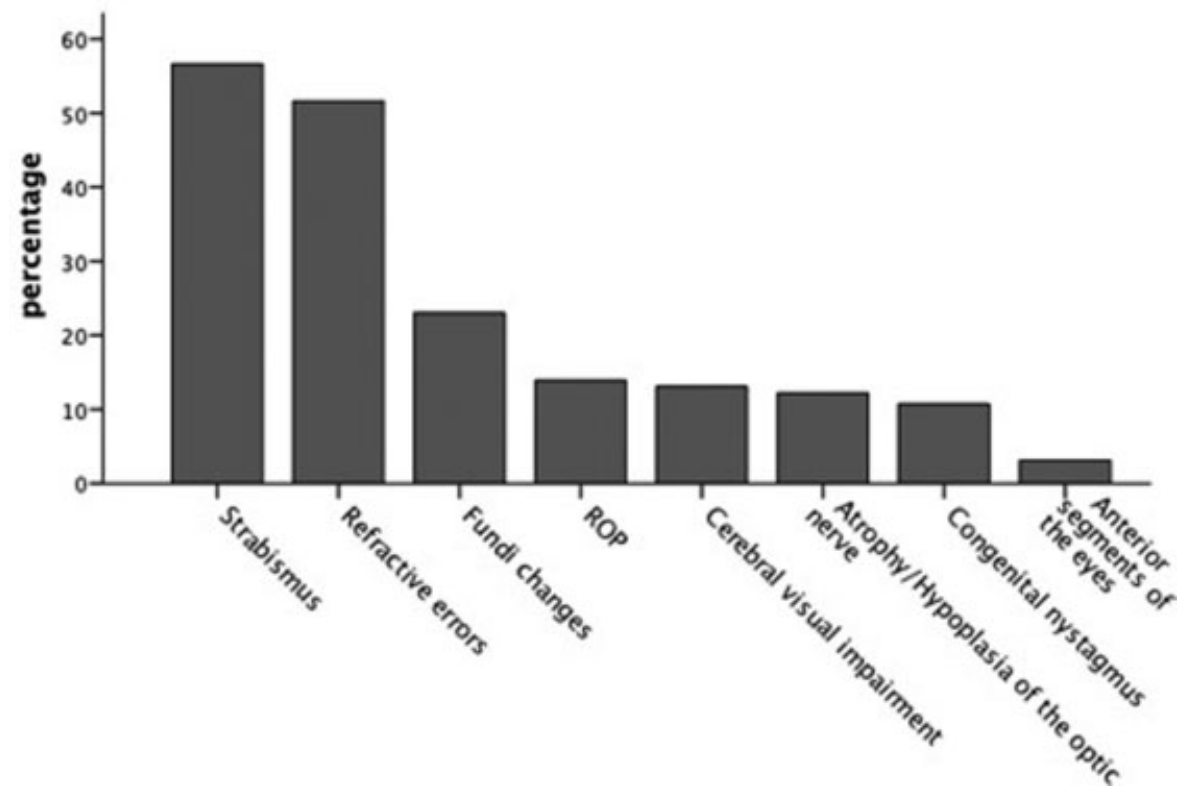

Fig. 1 Distribution of frequency of visual disorders. ROP, retinopathy of prematurity. 


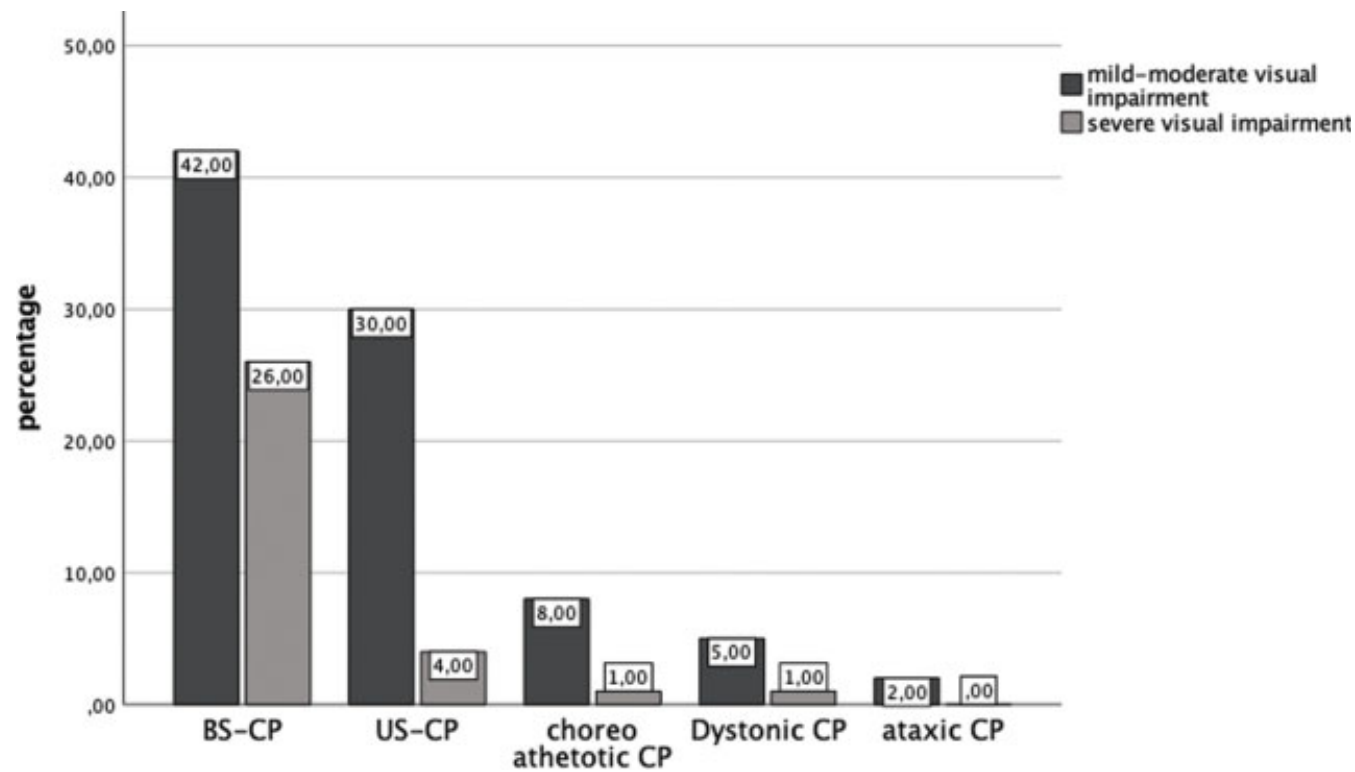

Fig. 2 Visual disorders related to different CP subtypes. BS, bilateral spastic; CP, cerebral palsy; US, unilateral spastic.

\section{Visual Impairment and CP-Subtype/Functional Classification}

Sixty-eight children with VI had BS-CP (57.2\%), followed by 34 (28.5\%) patients with US-CP. Predominantly, children with BS-CP showed severe VI. No child with ataxic CP showed severe VI (-Fig. 2).

The majority of children with $\mathrm{CP}$ and mild-moderate VI were classified as GMFCS/BFMF levels I and II. In contrast, more children with severe VI were assigned to GMFCS/BFMF levels III to $\mathrm{V}$ than to levels I and II ( - Figs. 3 and $\mathbf{4}$ ).

The association between VI (mild/severe) and GMFCS (I-II/III-V) was statistically significant (chi-square $=8.7$, $p=0.03$ ). The association between VI (mild/severe) and BFMF (I-II/III-V) was also statistically significant (chi-square $=9.5, p=0.02$ ).

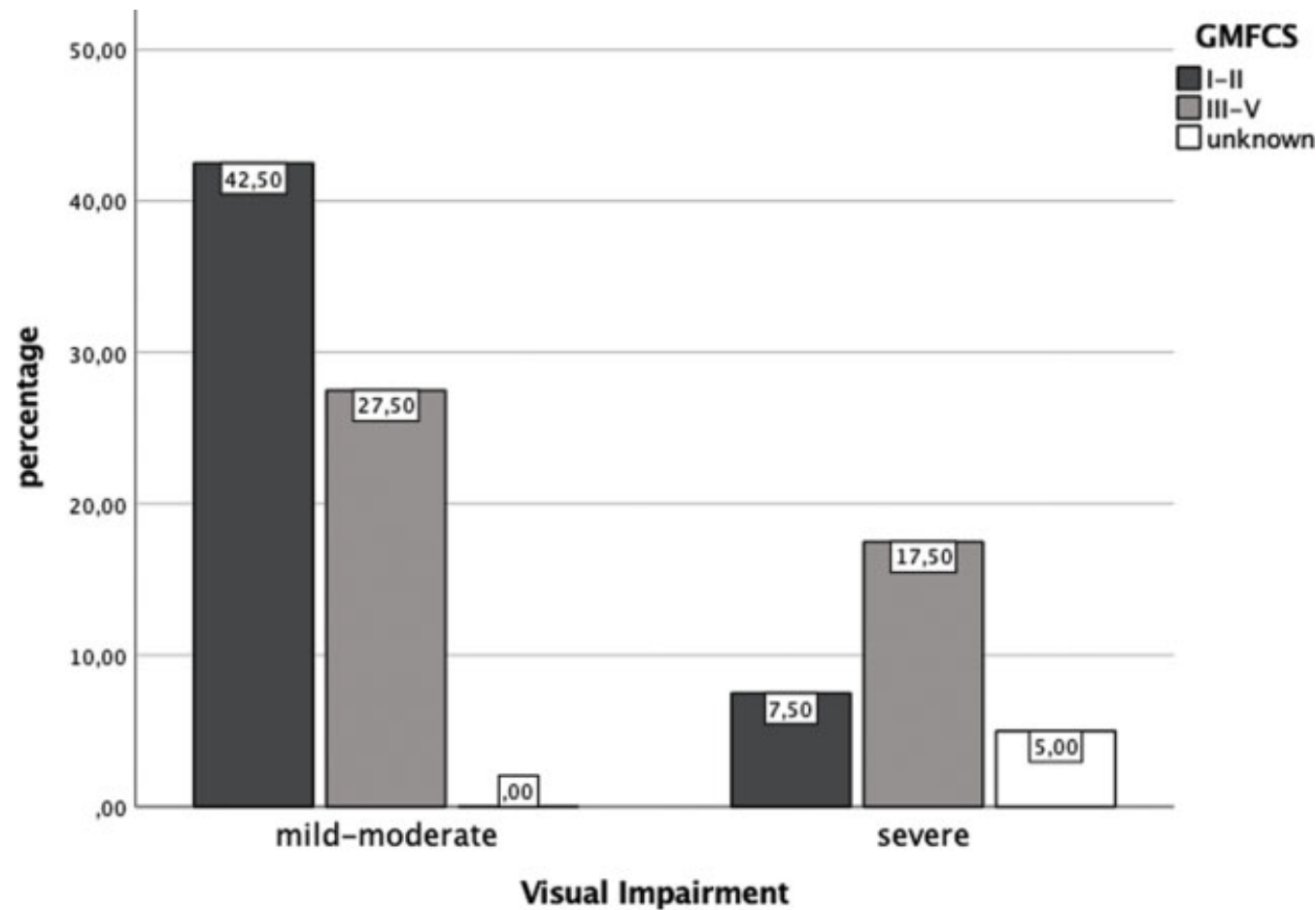

Fig. 3 Visual disorders related to different levels of severity of CP measured with GMFCS. CP, cerebral palsy; GMFCS, Gross Motor Function Classification System. 


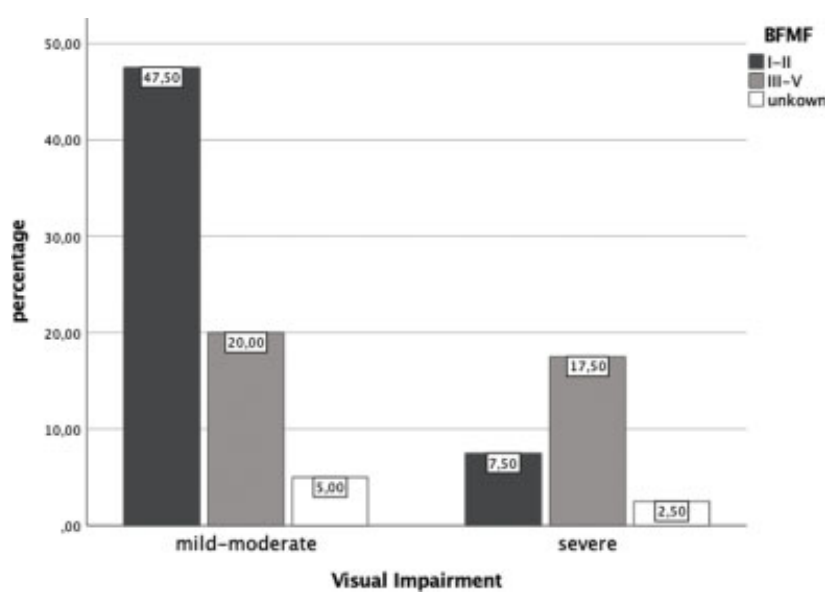

Fig. 4 Visual disorders related to different levels of severity of CP with BFMF. CP, cerebral palsy; BFMF, Bimanual Fine Motor Function.

\section{Strabismus}

Of all children with VI $(n=119)$, strabismus was diagnosed in 69 (57.9\%). In 21 (17.6\%) children, it was not known if strabismus was present. Of all children with strabismus, 43 (62.3\%) patients had esotropia and 26 (37.7\%) exotropia. Most common CP subtype found was spastic CP with 62 (90\%) children. Thirty-seven (53.6\%) children with strabismus had GMFCS III to V, and 25 (36.2\%) had BFMF III to V.

Twenty-one (48.8\%) children with esotropia had GMFCS I to II and 21 (48.8\%) children had GMFCS III to V, and 1 patient was unknown. Twenty-five (58.1\%) of the esotropic children had BFMF I and II and 15 (34.8\%) had BFMF III to V, and 3 patients were unknown. Twelve (46.2\%) of exotropic children had GMFCS I to II and 13 (50\%) had GMFCS III to V, and 1 patient was unknown. Seventeen (65\%) of exotropic children had BFMF I and II and 8 (30.8\%) had BFMF III to V, and 1 patient was unknown.

\section{Refractive Errors}

Of all children with VI $(n=119)$, refractive errors were found in 63 (52.9\%). Fifty-one (80.9\%) of the children with refractive errors had hyperopia, seven (11.1\%) had myopia, and five (7.9\%\%) had hyperopia on one eye and myopic changes on the other eye. Thirty-nine (61.9\%) of the infants were diagnosed with astigmatism. Three (4.8\%) of them showed pure astigmatic changes, 4 (6.3\%) astigmatism and myopia, and 32 (50.8\%) astigmatism and hyperopia. Anisometropia was found in 10 (15.9\%) patients.

Of 51 patients with hyperopia, 25 had mild hyperopia with $<+1.5 \mathrm{D}, 17$ had moderate hyperopia between $+1.6 \mathrm{D}$ and $+4 \mathrm{D}$, and 9 had high hyperopia with $>+4 \mathrm{D}$. Forty-two $(82 \%)$ of the infants with hyperopic changes had spastic $\mathrm{CP}$, and 9 (18\%) had other CP subtypes, and the greater majority of children was classified as GMFCS/BFMF I and II.

Of the seven infants diagnosed with myopia, one had mild myopia with $<-1.5 \mathrm{D}$, two had a moderate myopia between $-1.6 \mathrm{D}$ and $-4 \mathrm{D}$, and four had high myopia with $>-4 \mathrm{D}$. Spastic CP was diagnosed in six patients with myopia, and one child had choreoathetotic $\mathrm{CP}$. The majority of children had more severe forms of CP and was classified GMFCS/BFMF III to $\mathrm{V}$.

Among children with mild forms of CP (GMFCS/BFMF levels I and II), hyperopia (both low-moderate and high hyperopia) and high myopia were more frequent. Among severely affected children with GMFCS/BFMF levels III to V, low-moderate myopia was more frequent.

Astigmatism was detected in 39 patients and distribution among functional scores showed two peaks in GMFCS levels I and V.

\section{Visual Acuity}

Of the children with $\mathrm{CP}$ tested at the Medical University Innsbruck, testing for visual acuity was possible in 47 (36.4\%) children. More than $90 \%$ of the infants who were able to perform testing had spastic CP. Information was not available in 24 cases. In the remaining 58 cases, testing was not possible. For children tested elsewhere, information was missing. Twenty-three (17.8\%) patients had a visual acuity $>0.8,10(7.8 \%)$ between 0.4 and $0.7,9(6.9 \%)$ between 0.1 and 0.3 , and $5(3.8 \%)$ of the children had visual acuity $<0.1$. Patients without the possibility for testing had more severe forms of CP and were grouped into GMFCS/BFMF III to V.

\section{Retinopathy of Prematurity, Cerebral Visual Impairment, Optic Atrophy/Hypoplasia, Nystagmus, and Others}

Seventeen (14.2\%) of all children with VI were diagnosed with ROP. Seven (5.7\%) had ROP stages I to II and 10 (8.2\%) had ROP stages III to IV. No child had ROP stage V. Eleven (64.7\%) children with ROP had GMFCS I and II and 12 (70.6\%) children were BFMF I and II.

Sixteen (13.4\%) children with VI were diagnosed with severe CVI. Fourteen (88\%) of those patients had BS-CP, one child had US-CP, and one child dystonic CP. Thirteen (81\%) were classified as GMFCS III to V and nine (56\%) had a BFMF of III to V. In three cases, the BFMF was not available.

Fifteen (12.6\%) of CP children with VI were diagnosed with atrophy/hypoplasia of the optic nerve. All of those children had spastic CP. Most of them (73\%) had severe forms of CP and were classified as GMFCS III to V.

Thirteen (10.9\%) of the children with VI were diagnosed with nystagmus. Ten (83\%) had BS-CP, two (17\%) had US-CP, and one child had ataxic CP. Dystonic and choreoathetotic subtypes were not represented. Nine (69\%) and six (46\%) had GMFCS and BFMF levels III to V (-Table 1).

Only in four (3.3\%) patients with VI abnormalities on the anterior segments of the eyes were found including two children with congenital cataract, one child with occlusio pupillae (fibrotic membrane across the pupil), and one child with ROP stage III who developed a secondary glaucoma.

\section{Discussion}

VI seems to be an important comorbidity in children with CP. Almost two-third of the $\mathrm{CP}$ patients had a wide range of visual problems. Main VI found was strabismus and refractive errors followed by ROP, CVI, and optic atrophy. Our 
results are in line with previous studies, where strabismus and refractive errors were found as common visual disorders among CP children. ${ }^{4,17,21-26}$

In the present study, most children with VI had BS-CP, followed by US-CP, whereas no child with ataxic CP had a severe VI. Our results indicate that 1 in 10 children with $\mathrm{CP}$ has a severe VI or is blind, that is, approximately in accordance to the results of Novak et al. ${ }^{8}$

The two functional grading systems, GMFCS and BFMF, strongly correlate with each other. Children with $\mathrm{CP}$ and GMFCS/BFMF levels between III and V had a higher frequency of severe VI and were additionally at greater risk for severe cognitive impairment with IQ levels $<50$ and epilepsy. Moreover, brain malformations and extreme prematurity with hypoxia and/or neonatal encephalopathy were also associated with an increased risk for severe VI. Not surprisingly, children with brain malformations were at risk for developing CVI.

Due to the correlation of functional scores and VI found in our data, it seems to be important to consider the possibility of VI influencing the activities and participation of children with CP. Additionally, the functioning of a child with CP in vision-related activities, particularly in the presence of comorbidities as gross motor limitations, could be an important variable. Moreover, psychological well-being influenced by daily experiences is an important aspect. Studies have shown that reducing $\mathrm{CP}$ comorbidities had a positive effect on psychological quality of life of children. ${ }^{27}$ Therefore, treatment of VI as comorbidity of $\mathrm{CP}$ could be very helpful for the development of children by facilitating daily life actions and increasing health-related quality of life.

Incidence of strabismus among neurologically healthy children is greater than 3 to $13 \%$. Therefore, according to our data, a child with $\mathrm{CP}$ has an 8- to 38-time chance for developing strabismus than a non-CP child. ${ }^{28-30}$ Mainly, children with a spastic $\mathrm{CP}$ subtype were diagnosed with strabismus, but no correlation between the severity of $\mathrm{CP}$ and presence of strabismus could be found.

Incidence of refractive errors strongly varies among non$\mathrm{CP}$ children and occurred more often in CP children than in healthy children. ${ }^{28-30}$ Most common types of ametropia among CP children were hyperopia and astigmatism. Compared with the study by Saunders et al, myopia and anisometropia were less frequent probably due to a different definition of anisometropia. ${ }^{5}$ Saunders et al defined significant anisometropia as $\geq 1.00 \mathrm{D}$ between the corresponding meridians of the right and left eyes, in contrast, we defined anisometropia as $>1.5 \mathrm{D}$ between the corresponding meridians. $^{5}$ Children with mild forms of $\mathrm{CP}$ had more often hyperopia (both low-moderate and high hyperopia). Among severe cases, low-moderate myopia was more frequent, but surprisingly, this was not the case with high myopia in this study. In contrast to our data, Ghasia et al found that children with level V disease were at greatest risk for high myopia. ${ }^{30}$

The main limitation of the present study is the lack of prospective data. Due to retrospective evaluation of the data, it was not possible to gain information concerning subse- quent development of visual disability and functional classification over time.

\section{Conclusion}

Impaired vision is a significant problem in children with $\mathrm{CP}$ and should be considered in routine follow-up. All patients, especially those diagnosed with spastic CP, should undergo detailed ophthalmologic and orthoptic assessment as soon as the diagnosis $\mathrm{CP}$ is made. In addition, regular visual screening in children with $\mathrm{CP}$ seems to be important. As some disorders might not become evident at a certain age, there is a challenge to detect VI in very young children. Especially those diagnosed with severe forms of CP are likely to develop severe VI. Early diagnosis, intervention, and therapy should improve their overall function.

Conflict of Interest

None declared.

\section{References}

1 Krägeloh-Mann I, Cans C. Cerebral palsy update. Brain Dev 2009; 31(07):537-544

2 Pakula AT, Van Naarden Braun K, Yeargin-Allsopp M. Cerebral palsy: classification and epidemiology. Phys Med Rehabil Clin N Am 2009;20(03):425-452

3 Rosenbaum P, Paneth N, Leviton A, et al. A report: the definition and classification of cerebral palsy April 2006. Dev Med Child Neurol Suppl 2007;109:8-14

4 Black P. Visual disorders associated with cerebral palsy. Br J Ophthalmol 1982;66(01):46-52

5 Saunders KJ, Little JA, McClelland JF, Jackson AJ. Profile of refractive errors in cerebral palsy: impact of severity of motor impairment (GMFCS) and CP subtype on refractive outcome. Invest Ophthalmol Vis Sci 2010;51(06):2885-2890

6 Woo SJ, Ahn J, Park MS, et al. Ocular findings in cerebral palsy patients undergoing orthopedic surgery. Optom Vis Sci 2011;88 (12):1520-1523

7 Dufresne D, Dagenais L, Shevell MIREPACQ Consortium. Spectrum of visual disorders in a population-based cerebral palsy cohort. Pediatr Neurol 2014;50(04):324-328

8 Novak I, Hines M, Goldsmith S, Barclay R. Clinical prognostic messages from a systematic review on cerebral palsy. Pediatrics 2012;130(05):e1285-e1312

9 Ego A, Lidzba K, Brovedani P, et al. Visual-perceptual impairment in children with cerebral palsy: a systematic review. Dev Med Child Neurol 2015;57(Suppl 2):46-51

10 Mitry D, Williams C, Northstone K, et al. Perceptual visual dysfunction, physical impairment and quality of life in Bangladeshi children with cerebral palsy. Br J Ophthalmol 2016;100(09): $1245-1250$

11 Schenk-Rootlieb AJ, van Nieuwenhuizen O, van Waes PF, van der Graaf Y. Cerebral visual impairment in cerebral palsy: relation to structural abnormalities of the cerebrum. Neuropediatrics 1994; 25(02):68-72

12 Fazzi E, Signorini SG, LA Piana R, et al. Neuro-ophthalmological disorders in cerebral palsy: ophthalmological, oculomotor, and visual aspects. Dev Med Child Neurol 2012;54(08):730-736

13 Boyaci A, Akal A, Tutoglu A, et al. Relationship among ocular diseases, developmental levels, and clinical characteristics of children with diplegic cerebral palsy. J Phys Ther Sci 2014;26 (11):1679-1684 
14 Ottman R, Lipton RB. Comorbidity of migraine and epilepsy. Neurology 1994;44(11):2105-2110

15 Ottman R, Lipton RB, Ettinger AB, et al. Comorbidities of epilepsy: results from the Epilepsy Comorbidities and Health (EPIC) survey. Epilepsia 2011;52(02):308-315

16 Rosenbaum PL, Palisano RJ, Bartlett DJ, Galuppi BE, Russell DJ. Development of the Gross Motor Function Classification System for cerebral palsy. Dev Med Child Neurol 2008;50(04):249-253

17 Beckung E, Hagberg G. Neuroimpairments, activity limitations, and participation restrictions in children with cerebral palsy. Dev Med Child Neurol 2002;44(05):309-316

18 Boot FH, Pel JJ, van der Steen J, Evenhuis HM. Cerebral visual impairment: which perceptive visual dysfunctions can be expected in children with brain damage? A systematic review. Res Dev Disabil 2010;31(06):1149-1159

19 Lanzi G, Fazzi E, Uggetti C, et al. Cerebral visual impairment in periventricular leukomalacia. Neuropediatrics 1998;29(03): 145-150

20 Weinstein JM, Gilmore RO, Shaikh SM, et al. Defective motion processing in children with cerebral visual impairment due to periventricular white matter damage. Dev Med Child Neurol 2012;54(07):e1-e8

21 Andersen GL, Irgens LM, Haagaas I, Skranes JS, Meberg AE, Vik T. Cerebral palsy in Norway: prevalence, subtypes and severity. Eur J Paediatr Neurol 2008;12(01):4-13

22 Beckung E, Carlsson G, Carlsdotter S, Uvebrant P. The natural history of gross motor development in children with cerebral palsy aged 1 to 15 years. Dev Med Child Neurol 2007;49(10): 751-756

23 Himmelmann K, Beckung E, Hagberg G, Uvebrant P. Gross and fine motor function and accompanying impairments in cerebral palsy. Dev Med Child Neurol 2006;48(06):417-423

24 Kozeis N, Anogeianaki A, Mitova DT, Anogianakis G, Mitov T, Klisarova A. Visual function and visual perception in cerebral palsied children. Ophthalmic Physiol Opt 2007;27(01):44-53

25 Sasmal NK, Maiti P, Mandal R, et al. Ocular manifestations in children with cerebral palsy. J Indian Med Assoc 2011;109(05): 318-323

26 Preslan MW, Novak A. Baltimore Vision Screening Project. Ophthalmology 1996;103(01):105-109

27 Tessier DW, Hefner JL, Newmeyer A. Factors related to psychosocial quality of life for children with cerebral palsy. Int J Pediatr 2014;2014:204386

28 Kvarnström G, Jakobsson P, Lennerstrand G. Visual screening of Swedish children: an ophthalmological evaluation. Acta Ophthalmol Scand 2001;79(03):240-244

29 Newman DK, Hitchcock A, McCarthy H, Keast-Butler J, Moore AT. Preschool vision screening: outcome of children referred to the hospital eye service. Br J Ophthalmol 1996;80(12): 1077-1082

30 Ghasia F, Brunstrom J, Gordon M, Tychsen L. Frequency and severity of visual sensory and motor deficits in children with cerebral palsy: gross motor function classification scale. Invest Ophthalmol Vis Sci 2008;49(02):572-580 